\title{
Performance and Persistence Tests of Islamic Market Indices
}

\section{Kaouther FLIFEL*}

Doctor in Management Sciences, Institut Des Hautes Etudes Commerciales, Site archéologique de Carthage, Tunisia

\begin{abstract}
In a depressed global Economy and characterized by a severe crisis in the global financial system, Islamic Finance was distinguished by its resilience to the crisis. The performance of Islamic Finance tools, such as stock indices, has been the subject of several academic researches. However, the results have been conducted so far are divergent on the outperformance or underperformance of this category of indices, hence the importance of this first analysis in this area. The article presents the analytical approach leading to different performance tests before presenting the Islamic market indices that constitute our scope. Our first results help us to demonstrate that Islamic indices are not less efficient than conventional indices.
\end{abstract}

Keywords: Performance; Persistence; Islamic indices; Carhart model

\section{Introduction}

Islamic Finance has become an important component of the international financial system, and its growth is among the fastest. Considered as a recent phenomenon, Islamic Finance, in its very recent experience ( 40 years), is growing by over $30 \%$ since 2000 . It has developed so vigorous grown so it has evolved from a rising industry towards a global market in which Muslims and non-Muslims work together and learn from each other in the development of appropriate products and services. London and Luxembourg have become the main seats of Islamic Finance.

Islamic Finance is known for a very flexible and less risky activity. This helped it to develop rapidly and to meet different demands. In addition to the financial windfall that it represents, Islamic Finance has a strong credibility, strengthened during the last economic crisis, it has fared better than conventional Banks. Indeed, Islamic Banks have managed to escape the worst effects of the financial crisis experienced in 2008 because they were not exposed to "subprimes" and toxic loans, and have maintained a strong link with the real Economy.

The Islamic financial strength comes from the fact that it does not cover derivatives products and is not engaged in speculation. Having started with large reserves of capital and liquidity, Islamic Banks are better equipped to withstand market shocks.

Islamic Finance is present, for years, in the United States, European countries, in the countries of Southeast Asia and the Gulf countries, and it begins to exist in other Arab countries, especially after the popular events experienced since December 2010. Thus, these political changes might suggest new economic opportunities. Indeed, various governments have indicated their willingness to have a range of Islamic financial products. This is the case for example of Tunisia, Libya and Egypt.

This research aims to contribute to the study of ethical Finance, particularly Islamic market indices. Faced with the lack of unanimity of previous studies, the article tries to solve some points detected in studies that treated these indices individually and try to propose an overall study. This raises the question, first, on the link between supply of Islamic Finance and secondly on its performance.

Indeed, the central issue of our work revolves around the question: What are the issues of Islamic indices, and do their performance is different from their conventional counterparts? The answer to this question will help to better understand how the Islamic Finance market, locate financial products in context and assess their performance.

\section{Literature Review}

The variety of financial products and services intended for individuals and institutional investors anxious to ethics in their portfolios, was designed by the Islamic financial engineering. This is how Islamic Finance has made its introduction in the financial markets, as Abdelhafid [1] said, proposing solutions to investors such as investment funds, market indices and Islamic bonds, called Sukuk. Their launch was part of the logic to offer investors a way to diversify their portfolios, allowing them to invest in accordance with their religious principles. This research proposes to study particular stock indices conform to Sharia precepts.

Islamic market indices are all built from a benchmark, to which are applied financial and extra-financial filtering criteria. As for Islamic investment funds, control and filtering tasks are performed by an independent Sharia committee expressing its opinions to companies that will be part of the index. This committee is also responsible for the quarterly review of the composition of each index. This leads to inclusions and exclusions made available to the public via press releases.

The literature on equity indices in Islamic Finance is not as abundant as research dealing with socially responsible indices. Nevertheless, it shows a lack of unanimity on the outperformance or underperformance of this category of indices, for two reasons. Firstly, in accordance with modern financial theory, Islamic equity indices can be assumed riskier than their conventional counterparts due to the lack of diversification [2].

Secondly, these same indices could be more profitable than their counterparts due to the fact that the companies included have passed financial and extra-financial filtering criteria [3-4]. This finding was also confirmed by recent research such as that of Abedifar et al. [5] where they have confirmed the superiority of performance of Islamic indices relative to their conventional counterparts.

*Corresponding author: Kaouther FLIFEL, Doctor in Management Sciences, Institut Des Hautes Etudes Commerciales, Site archéologique de Carthage, Tunisia, Tel: + 216-55 2258 23; E-mail: flifelkaouther@yahoo.fr

Received August 23, 2017; Accepted December 01, 2017; Published December 08, 2017

Citation: Kaouther FLIFEL (2017) Performance and Persistence Tests of Islamic Market Indices. Bus Eco J 8: 329. doi: 10.4172/2151-6219.1000329

Copyright: @ 2017 Kaouther FLIFEL. This is an open-access article distributed under the terms of the Creative Commons Attribution License, which permits unrestricted use, distribution, and reproduction in any medium, provided the original author and source are credited. 
Other researches have concluded that Islamic equity indices perform better during periods of rising than in periods of falling markets. Indeed, in a period of decline, Islamic equity indices may have risk-adjusted returns lower than their conventional counterparts because of the exclusion of companies operating in sectors such as alcohol, tobacco or gambling. These sin stocks [6] are known to be more resilient in times of crisis, or "recession-proof". Later research of Ho et al. [7] argues that Islamic equity indices have outperformed their counterparts in times of crisis.

Moreover, Islamic equity indices often contain shares of small capitalization companies, low debt and which may have potential for growth when the trend is up, argue [4]. Other works, like those of Girard and Hassan [8] as well as Binmahfouz and Hassan [9], think that performance differences can also be attributed to differences in management style.

\section{Performance of Islamic market indices: sample and data}

The sample of this study is composed of 57 Islamic indices. In addition, we retained more narrow indices, broad, global, sectorial, geographical as well as those classified by size for each Islamic index.

Indeed, the index families that we selected are the following:

- The family of Dow Jones Islamic Market (DJIM) which groups Islamic indices calculated by Dow Jones;

- The family of Islamic indices calculated by Standard and Poor's which is the benchmark index SP500 Sharia;

- The Islamic index of Malaysia, Kuala Lumpur Sharia Index (KLSE);

- The Islamic index of Indonesia, Jakarta Islamic Index (JII);

- Islamic indices calculated by Morgan Stanley Capital International (MSCI);

- The Islamic market indices based Financial Times Stock Exchange (FTSE).

To allow comparability of the indices, we verified that our sample indices are calculated by using weighted free-float market capitalization.

To collect the financial data, several databases were used depending on the nature and availability of the desired information. Thus, the databases searched are as follows: Reuters 3000 Xtra v.5.1 ${ }^{1}$, Fact set ${ }^{2}$ and Data stream ${ }^{3}$.

Thus, all the historical data start from the date of launch of the index or the first data available, and go up to the date of data collection, December 31, 2014

We proceeded to the collection of closing prices for all 114 stock indexes (conventional and Islamic) in our sample. Information on dividends of each index component companies was not always available. It is for this reason that we have worked on price indices. We worked on daily data in order to have sufficient historical data.

1'It was regularly consulted for the index data in real time, and the history of some stock indices. It has a portal dedicated to Islamic finance (Islamic Finance Gateway).

${ }^{2}$ It allowed to collect data on the risk-free rate and in some Islamic and conventional stock indices. Also, Factset was particularly helpful for collecting accounting data of the companies in the Islamic market index.

${ }^{3}$ It allowed primarily to access the list of family companies comprising the index Dow Jones Islamic Market.
The currency effect was taken into consideration when collecting data from financial databases. These databases provide stock indices expressed in several currencies (EUR, GBP, JPY, USD, etc.) in addition to the local currency. For our study, we took data expressed in US dollars (USD) because the US indices constitute the major part of our sample.

\section{Methodology}

\section{The study of stochastic characteristics}

Before any data processing, we started by studying the characteristics of stochastic time series of Islamic and conventional stock indices in our sample. To do this, we studied their autocorrelation function and stationary to see if the mean and variance are invariant or modified over time.

The study of stationary is made from the auto-correlation denoted $\rho \mathrm{k}$ to measure the correlation of the series with itself with $\mathrm{k}$ shift periods. Indeed, the function is expressed as:

$$
\rho k=\frac{\operatorname{Cov}\left(y_{t}, y_{t-k}\right)}{\sigma_{y_{t}} \sigma_{y_{t-k}}}
$$

The study of the autocorrelation was completed by the realizing the test of Ljung- Box [10] to verify the serial correlation.

To test the presence or absence of a unit root, we conducted the Augmented Dickey-Fuller test or ADF year by year, on Islamic market indices of the Dow Jones family [11]. The two hypotheses to be tested are as follows:

- $\quad \mathrm{H}(0)$ : Presence of unit root, "non-stationary process"

- $\quad \mathrm{H}(1)$ : Absence of unit root, "stationary process"

The realization of this test will allow us to detect any possible nonstationary and know its type (deterministic or random).

In addition, we conducted the normality test of Jarque and Bera [12].

After the test, the decision rule is: If $J B>x_{2,1-\alpha}^{2}$, we reject $\mathrm{H}(0)$ the assumption of normality threshold $\alpha$.

\section{Performance measurement per family of Islamic market indices}

This analytical step consists in applying a number of performance measures to Islamic and conventional stock indices. The selection covered a wide range of measures ranging from the classics such as the Sharpe ratio and Treynor, to more recent such as the omega, or measures taking into account the skewness and kurtosis.

We note that for all measurements (in this work was retained 21 measures), which compare the performance of a portfolio to a profitability reserve or to an expected level, we use the risk-free rate $\mathrm{RF}$ as reference.

Using these measurements, we compared the performance of each index family taking into account the profitability and risk. Also, another comparison was made on Islamic indices of the Dow Jones family by using the analysis by size, sector and geographic area.

At the end of these comparisons, we established the classification of Islamic market indices given by the 21 performance measures selected. These do not obey all the same logic and may not give the same ranking [13]. 


\section{The persistence of performance}

We propose to study the persistence of the performance of Islamic market indices taking as an example the US companies included in the Dow Jones Islamic Index for the period from January 2004 to December 2014.

The model that we have adopted is that 4 factors Carhart [14]. Its expression is as follows:

$$
\left(\mathrm{R}_{\mathrm{t}}-\mathrm{R}_{\mathrm{ft}}\right)=\alpha+\beta\left(\mathrm{R}_{\mathrm{mt}}-\mathrm{R}_{\mathrm{ft}}\right)+\beta_{s} \mathrm{SMB}_{\mathrm{t}}+\beta_{\mathrm{h}} \mathrm{HML}_{\mathrm{t}}+\beta_{\mathrm{u}} \mathrm{UMD}_{\mathrm{t}}+\varepsilon_{\mathrm{t}}
$$

The variables SMB, HML and UMD are estimated using the methodology proposed by Fama and French [15], Carhart [14] and Carmichael et al. [16]. Thus, the process begins with a first step in grading and portfolio construction and then move to a second step of calculating the returns of portfolios obtained before reaching a third stage of regression. Indeed, the first step, called grading, is to divide the sample into several portfolios by size, management style and persistence in performance. The classification made at the end of each year gives the following groups:

- Two groups classified by size, measured by market capitalization: $50 \%$ of the shares are considered small caps (S) and $50 \%$ are big caps (B).

- Three groups classified by the ratio Book to Market: The first 30\% (first three declines) are regarded with a high ratio $(\mathrm{H})$ synonymous of a style of management called "value". The following are $40 \%$ of average ratio (M), while the last $30 \%$ (last three declines) are considered low $(\mathrm{L})$ which means that their management style is "growth".

- Two groups classified by the persistence of performance: The first 30\% (first three declines) are considered securities "winners" who continue to rise (U) and the last 30\% (last three declines) are the titles "losers" which continue to decline (D) (Table 1).

Thus, the SMB and HML factors are calculated annually based on the profitability of the six portfolios ( $\mathrm{SL}, \mathrm{SH}, \mathrm{SM}, \mathrm{BL}, \mathrm{BH}, \mathrm{BM}$ ) made each year based on the size (measured by market capitalization) and value effect business (measured by the ratio Book to Market). Each company in the index is classified in one of six portfolios made (Table 2).

Four other wallets are formed by the intersection of the two criteria of size and Momentum effect (or inertia effect). The latter measures the performance of portfolios "winners" and "losers" whose composition is changing every month. Indeed, the winners' portfolio is composed of $30 \%$ of the companies that had the strongest returns in the last 11 months. The portfolio of "losers", meanwhile, is composed of the shares that recorded the lowest rate of return over the same period.

Thus, the HML variable for the month " $\mathrm{m}$ " is measured by the geometric return of each of profitability portfolios made. These are equally weighted as proposed by Carhart [14]. We also note that the number of firms that contains each portfolio varies based on rankings made. At the end of this ranking, each firm belongs annually to one of the two portfolios which, depending on size and at the same time to one of the three portfolios constituted under the Book to Market (Table 3).

After having made the various portfolios, the 3 factors SMB, HML and UMD are calculated as follows:

$$
\begin{aligned}
& S M B=\frac{(S L-B L)+(S M-B M)+(S H-B H)}{3} \\
& H M L=\frac{(S H-S L)+(\mathrm{BH}-\mathrm{BL})}{2} \\
& U M D=\frac{(S U-S D)+(\mathrm{BU}-\mathrm{BD})}{2}
\end{aligned}
$$

Belonging to ethics, Islamic indices are characterized by their sustainability of investments and their particular orientations towards the study of the long term. The present article aims to examine their resistance during periods of recession. Indeed, we add to the previous model a dummy variable $\left(D^{\prime}\right)$ which will be equal to 1 if there is a recession, otherwise it will be zero. The periods of rising and falling correspond to the periods set by the National Bureau of Economic Research (NBER).

The new model taking into account the economic situation becomes:

$$
\begin{aligned}
& \left(\mathrm{R}_{\mathrm{t}}-\mathrm{R}_{\mathrm{ft}}\right)=\alpha+\beta\left(\mathrm{R}_{\mathrm{mt}}-\mathrm{R}_{\mathrm{ft}}\right)+\beta_{\mathrm{s}} \mathrm{SMB}_{\mathrm{t}}+\beta_{\mathrm{h}} \mathrm{HML}_{\mathrm{t}}+\beta_{\mathrm{u}} \mathrm{UMD}_{\mathrm{t}}+\alpha^{\prime} \mathrm{D}^{\prime}+\beta^{\prime} \mathrm{D}^{\prime} \\
& \left(\mathrm{R}_{\mathrm{mt}}-\mathrm{R}_{\mathrm{ft}}\right)+\beta_{\mathrm{s}}^{\prime} \mathrm{D}^{\prime} \mathrm{SMB}_{\mathrm{t}}+\beta^{\prime}{ }_{h} D^{\prime} H M L_{t}+\beta^{\prime}{ }_{\mathrm{u}} \mathrm{D}^{\prime} \mathrm{UMD}_{\mathrm{t}}+\varepsilon_{\mathrm{t}}
\end{aligned}
$$

\section{Results}

\section{The study of stochastic characteristics}

At first, our analysis focuses on the daily values of Islamic and conventional indices sample.

As an example, we show the results for the DJIMKT index. Thus, the correlogram of Figure 1 obtained by using the software Eviews, with twenty delay periods, shows the results of simple autocorrelation functions (column AC) and partial one (column PAC) (Figure 1).

The question here is to know what correlation coefficients are statistically different from zero at the selected threshold (5\%). The column on the Jung-Box statistic (Q-Stat) is used to reject the hypothesis

\begin{tabular}{|l|l|l|l|}
\hline Size & $\mathbf{5 0 \%}$ S (below the median) & $\mathbf{5 0 \%}$ B (above the median) \\
\hline Book to Market & $30 \% \mathrm{H}$ (3 first declines) & $40 \% \mathrm{M}$ (declines (4 to 7) & $30 \% \mathrm{~L} \mathrm{(3} \mathrm{last} \mathrm{declines)}$ \\
\hline Momentum & $30 \% \mathrm{U}$ (3 first declines) & & $30 \% \mathrm{D} \mathrm{(3} \mathrm{last} \mathrm{declines)}$ \\
\hline
\end{tabular}

Table 1: Size factor calculation methodology, book to market and momentum.

\begin{tabular}{|l|c|c|c|}
\hline & High Book to Market & Median Book to Market & Low Book to Market \\
\hline Big caps & $\mathrm{BH}$ & $\mathrm{BM}$ \\
\hline Small caps & $\mathrm{SH}$ & $\mathrm{SM}$ \\
\hline
\end{tabular}

Table 2: Constitution of portfolios by the size factor intersection and book to market.

\begin{tabular}{|c|c|c|}
\hline & Winners (Up) & Losers (Down) \\
\hline Big caps & BU & BD \\
\hline Small caps & SU & SD \\
\hline
\end{tabular}

Table 3: Constitution of portfolios by the intersection of two factors: size and momentum winners. 


\begin{tabular}{|c|c|c|c|c|c|c|}
\hline Autocorrelation & Partial Correlation & & $\mathrm{AC}$ & PAC & Q-Stat & Prob \\
\hline & 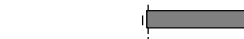 & 1 & 0.994 & 0.994 & 2602.0 & 0.000 \\
\hline & 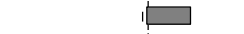 & 2 & 0.991 & 0.290 & 5191.8 & 0.000 \\
\hline & 吊 & 3 & 0.989 & 0.096 & 7769.6 & 0.000 \\
\hline & i & 4 & 0.986 & 0.027 & 10335. & 0.000 \\
\hline & $\dot{\phi}$ & 5 & 0.984 & $-0.00 \ldots$ & 12888. & 0.000 \\
\hline & $\phi$ & 6 & 0.981 & 0.016 & 15428. & 0.000 \\
\hline & 中 & 7 & 0.979 & 0.020 & 17958. & 0.000 \\
\hline & $\dot{\phi}$ & 8 & 0.977 & 0.011 & 20477. & 0.000 \\
\hline & $\dot{4}$ & 9 & 0.974 & 0.025 & 22986. & 0.000 \\
\hline & $\dot{\phi}$ & $1 \ldots$ & 0.972 & 0.016 & 25485 . & 0.000 \\
\hline & $\dot{\phi}$ & $1 \ldots$ & 0.970 & 0.017 & 27975 . & 0.000 \\
\hline & $\dot{\phi}$ & $1 \ldots$ & 0.968 & $-0.00 \ldots$ & 30455. & 0.000 \\
\hline & 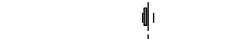 & $1 \ldots$ & 0.966 & $-0.01 \ldots$ & 32925. & 0.000 \\
\hline & i & $1 \ldots$ & 0.964 & $-0.01 \ldots$ & 35384 & 0.000 \\
\hline & i & $1 \ldots$ & 0.961 & $-0.01 \ldots$ & 37831. & 0.000 \\
\hline & $\dot{\phi}$ & $1 \ldots$ & 0.959 & 0.011 & 40269. & 0.000 \\
\hline & i & $1 \ldots$ & 0.957 & $-0.02 \ldots$ & 42695. & 0.000 \\
\hline & $\dot{\phi}$ & $1 \ldots$ & 0.954 & $-0.00 \ldots$ & 45109. & 0.000 \\
\hline & $\phi$ & $1 \ldots$ & 0.952 & 0.006 & 47513. & 0.000 \\
\hline & $\dot{q}$ & $2 \ldots$ & 0.950 & 0.004 & 49906. & 0.000 \\
\hline & $\dot{\phi}$ & $2 \ldots$ & 0.947 & $-0.00 \ldots$ & 52288. & 0.000 \\
\hline & $\phi$ & $2 \ldots$ & 0.945 & 0.015 & 54660. & 0.000 \\
\hline & $\dot{\phi}$ & $2 \ldots$ & 0.943 & 0.002 & 57022. & 0.000 \\
\hline & $\phi$ & $2 \ldots$ & 0.941 & $-0.00 \ldots$ & 59373. & 0.000 \\
\hline & 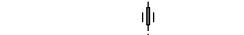 & $2 \ldots$ & 0.939 & 0.008 & 61715. & 0.000 \\
\hline & $\dot{\phi}$ & $2 \ldots$ & 0.936 & 0.009 & 64047 & 0.000 \\
\hline & 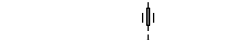 & $2 \ldots$ & 0.934 & 0.005 & 66370. & 0.000 \\
\hline & $\dot{\phi}$ & $2 \ldots$ & 0.932 & $-0.00 \ldots$ & 68683 & 0.000 \\
\hline & i & $2 \ldots$ & 0.930 & $-0.00 \ldots$ & 70985 . & 0.000 \\
\hline & $\dot{\phi}$ & $3 \ldots$ & 0.928 & $-0.00 \ldots$ & 73278 & 0.000 \\
\hline & $\dot{\phi}$ & $3 \ldots$ & 0.926 & 0.001 & 75562 . & 0.000 \\
\hline & $\dot{q}$ & $3 \ldots$ & 0.924 & 0.001 & 77835 . & 0.000 \\
\hline & $\phi$ & $3 \ldots$ & 0.921 & $-0.00 \ldots$ & 80099. & 0.000 \\
\hline & $\dot{q}$ & $3 \ldots$ & 0.919 & $-0.00 \ldots$ & 82353. & 0.000 \\
\hline & i & $3 \ldots$ & 0.917 & 0.016 & 84598. & 0.000 \\
\hline | & $\phi$ & $3 \ldots$ & 0.915 & 0.002 & 86834. & 0.000 \\
\hline
\end{tabular}

Figure 1: Correlogram DJIMKT.

$\mathrm{H}(0)$ of the nullity of coefficients. Q-Stat values are important and critical probabilities are all below 0.05 .

The Q-Stat which we reminded the calculation in the research methodology was obtained as follows: For example, for a delay q=3:

$$
Q=n(n+2) \sum_{k=1}^{q} \frac{\hat{p}_{k}^{2}}{n-k}=3634 \times 3632 \times\left(\frac{0,998^{2}}{3633}+\frac{0,996^{2}}{3632}-\frac{0,994^{2}}{3631}\right)=3636
$$

We note that this value is much greater than the tabulated value, read from the statistical chi-square table with 3 degrees of freedom.

We can deduce that there exists at least one autocorrelation coefficient statistically different from zero. This is confirmed by the analysis of autocorrelation and partial correlation columns that give the confidence intervals of the correlogram. All terms that are given interval by the horizontal dotted lines are statistically different from zero at the $5 \%$ level and we can conclude that the process of DJIMKT is not white noise.

Also, we note that the simple autocorrelation function given by the AC column decreases slowly which characterizes the non-stationary process. This is confirmed by recourse to the Augmented Dickey-fuller
(ADF) test. The critical probability obtained after realizing this test is to 0.5975 . It is greater than 0.05 which does not allow us to reject the null hypothesis of presence of unit root. DJIMKT process is not stationary in level.

To render the process stationary, we calculated the first differences such as:

$$
D(D J I M K T j)=(D J I M K T j)-(D J I M K T j-1) \text {. }
$$

The correlogram of Figure 2 shows the results of simple and partial autocorrelations D (DJIMKT) (Figure 2).

We also performed the ADF test. This allows to reject the hypothesis of unit root presence with a critical probability of 0.0000 , indicating that the process $\mathrm{D}$ (DJIMKT) is stationary and the DJIMKT series is well integrated with order 1 .

Annex 1 shows the results year by year for all Dow Jones index family in our sample for which the results corroborate the results found for the DJIMKT index.

The study of normality was made using the Jarque-Bera test [12] based on coefficients of skewness and kurtosis. 


\begin{tabular}{|c|c|c|c|c|c|}
\hline Autocorrelation & Partial Correlation & $A C$ & PAC & Q-Stat & Prob \\
\hline 미 & 口 & $-0.08 \ldots$ & $-0.08 \ldots$ & 18.668 & 0.000 \\
\hline 虫 & $\overrightarrow{a_{1}}$ & $2-0.04 \ldots$ & $-0.04 \ldots$ & 22.869 & 0.000 \\
\hline 10 & 1 & $3 \quad 0.040$ & 0.033 & 27.041 & 0.000 \\
\hline di & i & $-0.01 \ldots$ & $-0.01 \ldots$ & 27.595 & 0.000 \\
\hline di & $d_{1}$ & $5 \quad-0.04 \ldots$ & $-0.04 \ldots$ & 32.946 & 0.000 \\
\hline$\omega_{1}$ & i & $\begin{array}{ll}6 & 0.000\end{array}$ & $-0.01 \ldots$ & 32.946 & 0.000 \\
\hline i & पi & $-0.02 \ldots$ & $-0.02 \ldots$ & 34.215 & 0.000 \\
\hline$\phi_{1}$ & in & 0.008 & 0.007 & 34.398 & 0.000 \\
\hline i & il & $9-0.00 \ldots$ & $-0.00 \ldots$ & 34.496 & 0.000 \\
\hline i & 中 & $1 \ldots 0.028$ & 0.027 & 36.551 & 0.000 \\
\hline i & ii & $1 \ldots 0.002$ & 0.005 & 36.562 & 0.000 \\
\hline in & i & 1... 0.035 & 0.037 & 39.778 & 0.000 \\
\hline i & i & $1 \ldots-0.00 \ldots$ & $-0.00 \ldots$ & 39.902 & 0.000 \\
\hline di & a & $1 \ldots-0.03 \ldots$ & $-0.03 \ldots$ & 43.093 & 0.000 \\
\hline di & a & $1 \ldots-0.03 \ldots$ & $-0.04 \ldots$ & 46.914 & 0.000 \\
\hline |" & 中 & $1 \ldots 0.053$ & 0.045 & 54.330 & 0.000 \\
\hline$\|$ & $\|$ & $1 \ldots 0.006$ & 0.018 & 54.421 & 0.000 \\
\hline di & 口i & $1 \ldots-0.07 \ldots$ & $-0.07 \ldots$ & 70.859 & 0.000 \\
\hline i & in & $1 \ldots 0.014$ & $-0.00 \ldots$ & 71.363 & 0.000 \\
\hline 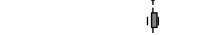 & in & $2 \ldots 0.028$ & 0.019 & 73.422 & 0.000 \\
\hline di & di & $2 \ldots-0.06 \ldots$ & $-0.04 \ldots$ & 82.810 & 0.000 \\
\hline i & $\|$ & $2 \ldots \quad 0.029$ & 0.018 & 85.068 & 0.000 \\
\hline i & i & 2... 0.001 & $-0.00 \ldots$ & 85.070 & 0.000 \\
\hline i & $i$ & $2 \ldots-0.02 \ldots$ & $-0.01 \ldots$ & 86.293 & 0.000 \\
\hline in & $i$ & $2 \ldots-0.00 \ldots$ & $-0.00 \ldots$ & 86.334 & 0.000 \\
\hline in & in & $2 \ldots 0.001$ & $-0.00 \ldots$ & 86.335 & 0.000 \\
\hline i & i & 2... 0.024 & 0.028 & 87.901 & 0.000 \\
\hline$\phi$ & ii & $2 \ldots \quad 0.003$ & 0.003 & 87.923 & 0.000 \\
\hline 1 & $\|$ & $2 \ldots \quad 0.002$ & 0.003 & 87.938 & 0.000 \\
\hline i & in & 3... 0.001 & 0.005 & 87.942 & 0.000 \\
\hline$i$ & i & $3 \ldots-0.00 \ldots$ & $-0.00 \ldots$ & 88.070 & 0.000 \\
\hline 10 & di & 3... 0.013 & 0.006 & 88.555 & 0.000 \\
\hline i & di & $3 \ldots-0.00 \ldots$ & $-0.00 \ldots$ & 88.590 & 0.000 \\
\hline d. & di & $3 \ldots-0.06 \ldots$ & $-0.05 \ldots$ & 98.722 & 0.000 \\
\hline 10 & di & 3... 0.019 & 0.009 & 99.720 & 0.000 \\
\hline 1) & 10 & $\begin{array}{ll}3 \ldots & 0.039\end{array}$ & 0.030 & 103.76 & 0.000 \\
\hline
\end{tabular}

Figure 2: Correlogram D(DJIMKT).

Performing the test shows that the JB statistic value is still very high compared to the tabulated value of chi-square for all indices without exception: $\mathrm{JB}^{\mathrm{x} \mathrm{x}_{2,0.95}^{2}}$ (Annex 2).

The critical probabilities are always lower than 0.05 , which allows rejecting the null hypothesis of normal distribution of closing prices of stock indices in our sample.

The Annex 2, which presents descriptive statistics of the Dow Jones index family, provides information on the symmetry of the distribution and its normality.

Indeed, we note that the median is systematically below average that is to say, the distribution is skewed and spread right. This is confirmed by the negative skewness for all indices except for four Islamic indices (DJIU50, DJWXUS, W1DOW and DJIFI).

The kurtosis shows that the distribution is leptokurtic, kurtosis is greater than 3 for all market indices in this family, and abnormal values upward or downward are quite frequent enabling us to conclude that the distribution does not follow a normal distribution.

This is confirmed by the Jarque-Bera test [12]. The critical probabilities (p-values) are all below 0.05 , which allows to reject the null hypothesis of normal distribution of returns of stock market indices of the Dow Jones family.

\section{Performance measurement of the Dow Jones family}

We used 21 different performance measures to classify Islamic indices in our sample. We also compared different measures to see the ranking given by each.

The indices of the Dow Jones family: Table 4 shows the results of calculations with the 21 performance measurements over the entire period of the study. It can be interpreted horizontally and vertically.

In fact, each line corresponds to a calculated measure for all the indices of the sample and gives the ranking obtained with this measurement 1 to $n$ (with " $n$ " the number of Islamic indices belonging to the same family). The columns, in turn, give the various measures calculated for each stock index and allowing rankings comparisons obtained with different measures.

We note that four indices (DJIMUK, DJIMUS, DJIULC, DJIU50) have a Sharpe ratio (Sharpe 1) negative, which means that their average profitability over the period was lower than the risk free rate. The same result is found when we change risk measurement used, for example the measure of Sortino which is based on the semi-variance in the denominator or the Treynor ratio, based on systematic risk ( $\beta$ ), Sharpe VaR, STARR ratio.

When we consider the skewness, two of the previous four clues DJIU50, DJIMUS have a positive skewness meaning that the distribution is skewed and spread to the left and leptokurtic (all kurtosis higher than 3) characterizing the financial series. We get a Sharpe ratio $S / K$ negative for five indices (DJIMKT, DJIMJAP, DJIMUS, DJIULC and DJIU50) meaning that they have adjusted performance with the lowest risks. 


\begin{tabular}{|c|c|c|c|c|c|c|c|c|c|c|c|c|c|c|c|c|c|c|c|c|c|c|c|c|}
\hline \multirow[b]{2}{*}{ Sharpe 1} & \multicolumn{2}{|c|}{ DJIMKT } & \multicolumn{2}{|c|}{ DJIMCN } & \multicolumn{2}{|c|}{ DJIMJAP } & \multicolumn{2}{|c|}{ DJIMUK } & \multicolumn{2}{|c|}{ DJIMUS } & \multicolumn{2}{|c|}{ DJIULC } & \multicolumn{2}{|c|}{ DJIUMC } & \multicolumn{2}{|c|}{ DJIUSC } & \multicolumn{2}{|l|}{ DJIU50 } & \multicolumn{2}{|c|}{ DJIWDD } & \multicolumn{2}{|c|}{ DJIWEM } & \multicolumn{2}{|c|}{ DJIXUS } \\
\hline & 0.007 & -6 & 0.344 & -3 & 0.002 & -7 & -0.034 & -10 & -0.045 & -9 & -0.024 & -11 & 0.223 & -4 & 0.392 & -2 & $\mid-0.148$ & -12 & 0.091 & -8 & 0.294 & -1 & 0.196 & -5 \\
\hline Sharpe 2 & 0.004 & -6 & 0.117 & -3 & 0.003 & -7 & 0.099 & -10 & 0.001 & -9 & 0.095 & -11 & 0.016 & -4 & 0.12 & -2 & -0.006 & -12 & 0.103 & -8 & 0.02 & -1 & 0.112 & -5 \\
\hline Sharpe M & 0.007 & -6 & 0.344 & -3 & 0.002 & -7 & 0.097 & -10 & -0.001 & -9 & 0.095 & -11 & 0.223 & -4 & 0.392 & -2 & -0.005 & -12 & 0.101 & -8 & 0.294 & -1 & 0.196 & -5 \\
\hline Sortino & 0.034 & -6 & 1.396 & -3 & 0.007 & -7 & -0.271 & -10 & -0.253 & -9 & -0.6 & -11 & 1.223 & -4 & 1.716 & -1 & -0.835 & -12 & 0.045 & -8 & 0.6 & -2 & 0.616 & -5 \\
\hline Sharpe S/K & -0.019 & -6 & 0.276 & -4 & -0.026 & -7 & 0.029 & -10 & -0.043 & -9 & -0.015 & -11 & 0.194 & -3 & 0.363 & -1 & -0.131 & -12 & 0.071 & -8 & 0.254 & -2 & 0.158 & -5 \\
\hline Calmar & 0.014 & -6 & 0.549 & -4 & 0.004 & -7 & -0.067 & -10 & -0.102 & -9 & -0.182 & -11 & 0.521 & -3 & 0.101 & -1 & -0.34 & -12 & 0.08 & -8 & 0.714 & -2 & 0.327 & -5 \\
\hline Sterling & 0.011 & -6 & 0.776 & -2 & 0.003 & -7 & -0.044 & -10 & -0.089 & -9 & -0.142 & -11 & 0.508 & -4 & 0.789 & -1 & -0.28 & -12 & 0.083 & -8 & 0.593 & -3 & 0.269 & -5 \\
\hline RI & 0.016 & -6 & 0.12 & -2 & -0.006 & -11 & 0.103 & -9 & 0.052 & -1 & 0.109 & -7 & 0.011 & -6 & 0.115 & -4 & -0.012 & -12 & 0.097 & -10 & 0.015 & -5 & 0.103 & -8 \\
\hline Treynor & 0.005 & -6 & 0.41 & -2 & -0.004 & -7 & -0.005 & -12 & -0.03 & -9 & -0.014 & -10 & 0.147 & -5 & 0.293 & -3 & -0.104 & -11 & 0.093 & -8 & 0.487 & -1 & 0.101 & -4 \\
\hline Jensen & 0.003 & -6 & 0.179 & -2 & 0.001 & -7 & 0.086 & -10 & -0.007 & -9 & 0.076 & -11 & 0.06 & -4 & 0.181 & -1 & -0.028 & -12 & 0.121 & -8 & 0.067 & -3 & 0.12 & -5 \\
\hline Sharpe VaR & 0.005 & -7 & 0.249 & -3 & 0.002 & -7 & -0.06 & -10 & -0.027 & -9 & -0.025 & -11 & 0.136 & -4 & 0.278 & -2 & -0.089 & -12 & 0.095 & -8 & 0.179 & -1 & 0.159 & -5 \\
\hline R Var & 0.004 & -6 & 0.242 & -3 & 0.002 & -7 & 0.063 & -10 & -0.025 & -9 & 0.03 & -11 & 0.128 & -4 & 0.268 & -2 & -0.083 & -12 & 0.095 & -8 & 0.167 & -2 & 0.154 & -5 \\
\hline $\begin{array}{l}\text { Sharpe Var } \\
\text { C/F }\end{array}$ & 0.005 & -7 & 0.669 & -3 & 0.006 & -6 & -0.395 & -10 & -0.273 & -9 & -1.336 & -11 & 0.527 & -4 & 0.697 & -1 & -2.268 & -12 & 0.054 & -8 & 0.576 & -2 & 0.39 & -5 \\
\hline STARR & 0.003 & -6 & 0.192 & -3 & 0.001 & -7 & -0.076 & -10 & -0.016 & -9 & -0.054 & -11 & 0.084 & -4 & 0.21 & -1 & -0.055 & -12 & 0.097 & -8 & 0.111 & -1 & 0.137 & -5 \\
\hline Omega & 1.045 & -6 & 1.155 & -3 & 0.981 & -11 & 1.642 & -1 & 1.049 & -4 & 1.115 & -9 & 1.038 & -8 & 1.171 & -2 & 0.973 & -12 & 1.629 & -2 & 1.041 & -7 & 1.107 & -10 \\
\hline 《 d » ratio & 0.817 & -6 & 0.902 & -3 & 0.908 & -8 & 1.022 & -11 & 0.905 & -7 & 1.02 & -10 & 0.858 & -4 & 0.954 & -5 & 0.999 & -12 & 1.019 & -9 & 0.868 & -5 & 0.998 & -6 \\
\hline M2 & 0.028 & -6 & 0.171 & -1 & 0.028 & -7 & 0.115 & -10 & 0.019 & -9 & 0.105 & -11 & 0.067 & -4 & 0.179 & -3 & 0.001 & -12 & 0.125 & -8 & 0.079 & -1 & 0.144 & -5 \\
\hline MRAP & 0.032 & -6 & 0.437 & -3 & 0.022 & -7 & 0.021 & -12 & -0.003 & -9 & 0.04 & -10 & 0.174 & -5 & 0.319 & -2 & -0.077 & -11 & 0.119 & -8 & 0.514 & -1 & 0.278 & -4 \\
\hline eSDAR & 0.007 & -6 & 0.149 & -1 & 0.006 & -7 & 0.094 & -10 & -0.002 & -9 & 0.084 & -11 & 0.046 & -4 & 0.158 & -3 & -0.02 & -12 & 0.104 & -8 & 0.058 & -1 & 0.123 & -5 \\
\hline AP & -0.039 & -6 & 0.102 & -2 & -0.056 & -8 & 0.029 & -10 & -0.06 & -9 & 0.024 & -11 & -0.003 & -4 & 0.087 & -2 & -0.078 & -12 & 0.055 & -7 & 0.014 & -2 & 0.074 & -5 \\
\hline ASKSR & 0.09 & -11 & 0.632 & -3 & 0.092 & -10 & 0.226 & -12 & 0.101 & -9 & 0.393 & -7 & 0.505 & -4 & 0.736 & -1 & 0.364 & -5 & 0.127 & -12 & 0.714 & -1 & 0.42 & -6 \\
\hline Observation & 2634 & & 2634 & & 2634 & & 2634 & & 2634 & & 2634 & & 2634 & & 2634 & & 2634 & & 2634 & & 2634 & & 2634 & \\
\hline
\end{tabular}

Table 4: Performance measures applied to Islamic market indices of the dow jones family.

Considering the fact that none of the indices studied did manage to have a good ratio of Calmar or Sterling ratio because of the existence of extreme values corresponding to the historical maximum loss incurred in the period observed, the remaining five Indices (DJIMCN, DJIUMC, DJIUSC, DJIWEM, DJIXUS) can be assessed in the light of the absolute performance measures. Indeed, alpha of Jensen which measures the excess of actual risk-adjusted returns, shows a positive sign synonym to an outperformance of these indices. By adding the market risk to the portfolio, previous results are confirmed regardless of the risk measurement used, the total risk (the $\mathrm{M}^{2}$ measurement) or systematic risk (MRAP). After neutralization of the difference in risk between the index and the market, eSDAR measure allows us to clearly distinguish the two best indicators over the whole period, it is DJIMJAP and DJIWDD.

In terms of ranking, all measures allow the classification of Indices in descending order of ratios (the higher the ratio, the higher the index is interesting) with the exception of "d" ratio which ranks in ascending order of Indices ratio (stock index is particularly interesting that the "d" ratio is low). The Islamic index DJIWEM grouping emerging countries is considered the most powerful ( $\mathrm{n}^{\circ} 1$ in the ranking) with 11 measures while DJIU50 index is the worst performer in this category. It is classified in last position ( $\mathrm{n}^{\circ} 12$ in the ranking) by 17 of the 21 measures used.

Islamic sector indices Dow Jones family: The Dow Jones stock indices are classified according to ICB sectorial classification. The sector indices in this family are 10 in number, corresponding to the 10 industries that brings together the nomenclature. When we focus on the performance of the sector indices (Table 5), we note that all indices have a positive Sharpe ratio except DJIFI index for financial institutions. This shows the worst performance relative to the market and relative to the risk free rate regardless of risk measurement used (total risk, systematic, VaR, RBAF, Max Drawdown).
The omega ratio is less than one for three indices (DJICG, DJICS and DJITEL) which can be interpreted as insufficient earnings to cover losses for the period. Note that when using the maximum loss as a measure of risk, the Calmar ratio of all indices is less than unity reflecting the clear excess return does not allow the cover the maximum loss represented by the extreme value downward. The absolute measure AP of Aftalion and Poncet [17], which uses the additional returns required by extra risk point (risk premium) is negative for seven indices (DJIBM, DJICG, DJIFI, DJIHC, DJIND, DJITEL and DJIUT).

In terms of ranking, the DJIFI index is ranked in last position ( ${ }^{\circ} 10$ in the ranking) with 20 performance measures, just after DJITEC index DJIHC and displaying them as poor performance. However, the index of basic materials (DJIBM) is the most efficient according to the ranking prepared by the same measures, followed by DJIIND DJIOG indices related to industrial and oil sectors. The classification of regional indices established by Sharpe ratio vector is the same as that of 10 other measures (among 21 used).

Islamic indices classified by market capitalization: Over the entire period, Islamic Small Cap index seems to be better than its two counterparts in large and mid caps. Indeed, as illustrated in Tables 1-6, the DJIWS index shows a surplus of risk-adjusted returns superior to other indices.

This is nuanced by the Treynor ratio [18] or MRAP based on the beta of the index and by the measurement of Calmar and omega [19] which use loss as a measure of risk, this can be explained mainly by the higher volatility of DJIWS the index that offers better opportunities for gains in return for greater risk taking.

In terms of ranking, the index of small caps (DJIWS) is ranked first by 16 measures, and the index for large capitalizations (DJIWL) is considered the worst performer with 20 performance measures. Similarly, the classification established by the Sharpe ratio is 16 respected by other measures. 


\begin{tabular}{|c|c|c|c|c|c|c|c|c|c|c|c|c|c|c|c|c|c|c|c|c|}
\hline \multirow[b]{2}{*}{ Sharpe 1} & \multicolumn{2}{|c|}{ DJIBM } & \multicolumn{2}{|c|}{ DJICG } & \multicolumn{2}{|c|}{ DJICS } & \multicolumn{2}{|c|}{ DJIFI } & \multicolumn{2}{|c|}{ DJIHC } & \multicolumn{2}{|c|}{ DJIND } & \multicolumn{2}{|c|}{ DJIOG } & \multicolumn{2}{|c|}{ DJITEC } & \multicolumn{2}{|c|}{ DJITEL } & \multicolumn{2}{|c|}{ DJIUT } \\
\hline & 0.008 & -1 & 0.032 & -5 & 0.003 & -7 & -0.278 & -10 & 0.044 & -9 & .336 & -3 & .224 & -2 & 0.08 & -8 & 0.147 & -6 & 221 & -4 \\
\hline Sharpe 2 & 002 & -1 & .085 & -6 & 001 & -8 & 0.103 & -10 & .002 & -9 & 0.107 & -3 & 014 & -2 & 0.082 & -7 & 0.008 & -5 & 0.099 & -4 \\
\hline Sharpe M & 008 & -1 & 32 & -5 & 003 & -7 & .215 & -10 & 321 & -9 & -0.217 & -3 & 224 & -2 & 0.08 & -8 & .004 & -6 & 0.211 & -4 \\
\hline Sorti & 32 & -1 & & -5 & & -7 & & -1 & & -5 & & -3 & & & & & & -6 & & -4 \\
\hline Sharpe & & -1 & .036 & -5 & & -7 & & -10 & .04 & -9 & .327 & & 5 & & & $-\varepsilon$ & .13 & -6 & 0.241 & -3 \\
\hline almar & 12 & -1 & 47 & -5 & 02 & -6 & .269 & -10 & .104 & -9 & 384 & & 519 & & 899 & -8 & 342 & -7 & 122 & -4 \\
\hline Sterling & 012 & -1 & 464 & -5 & .004 & -7 & -0.356 & -10 & -0.088 & -9 & -0.454 & -3 & 509 & -2 & 477 & -8 & 279 & -6 & .229 & -4 \\
\hline RI & 014 & -1 & -0.082 & -6 & .008 & -8 & -0.0 & -10 & 018 & -9 & -0.093 & -3 & 09 & -2 & -0.087 & -7 & & -5 & & -4 \\
\hline Trey & 006 & -1 & 098 & -6 & -0.0 & -7 & & -10 & -0.029 & -9 & & -4 & 48 & -3 & & -8 & 03 & -5 & & -2 \\
\hline Jensen & 001 & -1 & .023 & -6 & & -7 & & -1 & & -9 & & & & & 1 & 8 & & -5 & & -3 \\
\hline Sharpe $V$ & 006 & -1 & .063 & -5 & 003 & -7 & .252 & -1 & -0.026 & $-\varsigma-\varsigma$ & -0.287 & - & 137 & -2 & -0.034 & -8 & 0.088 & -6 & 0.217 & -4 \\
\hline Var & 002 & -1 & & -5 & 0 & -7 & -0.139 & -1 & -0.027 & -9 & -0.172 & & 126 & - & 6 & -8 & 0.085 & -6 & 7 & -4 \\
\hline Sharpe Var C/F & 0.006 & -1 & 0.357 & -5 & 0.007 & -7 & -0.707 & -10 & -0.272 & -9 & -1.648 & -4 & .528 & -2 & 0.385 & -8 & -2.267 & -6 & 58 & -3 \\
\hline STARR ratio & 0.001 & -1 & 01 & -5 & -0.001 & -8 & -0.126 & -9 & -0.018 & -1 & -0.148 & -3 & 0.082 & -2 & 0.007 & -8 & -0.057 & -6 & -0.105 & -4 \\
\hline Omega & 1.046 & -2 & 0.843 & -2 & 0.982 & -8 & 1.332 & -10 & 1.052 & -7 & 1.203 & -10 & .039 & -3 & 1.359 & -7 & 0.974 & -5 & 1.317 & -4 \\
\hline «d » ratio & 315 & -1 & 711 & -4 & 906 & -7 & 822 & -1 & 903 & -9 & 818 & -6 & .856 & -3 & 0.752 & -5 & .997 & -9 & 7 & -2 \\
\hline M2 & 229 & -1 & .141 & -5 & 029 & -7 & .197 & -1 & & -9 & -0.207 & -3 & 0.068 & -2 & -0.133 & -8 & 0.002 & -6 & 187 & -4 \\
\hline MRA & & -1 & & -1 & 0.022 & -7 & -0.181 & $-1 C$ & 0.005 & -9 & -0.162 & -4 & 0.172 & -3 & 0.1 & -8 & -0.079 & -5 & -0.083 & -2 \\
\hline eSDAR & 008 & -1 & 0.163 & -1 & 0.007 & -7 & -0.218 & -10 & -0.001 & -9 & -0.228 & -3 & .047 & -2 & -0.154 & -8 & -0.019 & -6 & 0.208 & -4 \\
\hline AP & .041 & -1 & -0.102 & -1 & 0.058 & -7 & -0.173 & -10 & -0.062 & -8 & -0.178 & -3 & .005 & -2 & 0.115 & -9 & -0.08 & -6 & -0.147 & -4 \\
\hline ASKSR & 0.091 & -1 & 0.32 & -1 & 0.093 & -7 & -0.086 & -10 & 0.102 & -9 & 0.081 & -2 & 0.506 & -3 & 0.424 & -8 & 0.365 & -6 & -0.185 & -5 \\
\hline Observations & 2634 & & 2634 & & 263 & & 263 & & 263 & & 263 & & 263 & & 2634 & & 263 & & 2634 & \\
\hline
\end{tabular}

The values given in parentheses refer to the classification of an Islamic index for each of the performance measures.

Table 5: Performance measures applied to sectoral Islamic stock index (ICB) from Dow Jones family.

\begin{tabular}{|c|c|c|c|c|c|c|c|c|c|c|c|c|c|c|c|c|c|c|c|}
\hline \multirow{2}{*}{$\begin{array}{l}\text { 06-Jan } \\
\text { Sharpe } 1\end{array}$} & \multicolumn{2}{|c|}{ DJIWS } & \multicolumn{2}{|c|}{ DJIWM } & \multicolumn{2}{|c|}{ DJIWL } & \multirow{2}{*}{$\begin{array}{c}\text { 06-Feb } \\
\text { Sharpe } 1\end{array}$} & \multicolumn{2}{|c|}{ DJIGWE } & \multicolumn{2}{|c|}{ DJIGNO } & \multicolumn{2}{|c|}{ DJIGLA } & \multicolumn{2}{|c|}{ DJIGAU } & \multicolumn{2}{|c|}{ DJIGAP } & \multicolumn{2}{|c|}{ DJIGAM } \\
\hline & 0.224 & -1 & 0.08 & -2 & -0.147 & -3 & & 0.005 & -4 & 0.454 & -6 & 0.01 & -1 & 0.144 & -2 & 0.057 & -3 & 0.086 & -5 \\
\hline Sharpe 2 & 0.014 & -1 & -0.082 & -2 & -0.008 & -3 & Sharpe 2 & 0.104 & -4 & 0.217 & -6 & 0.103 & -1 & 0.199 & -2 & 0.141 & -3 & 0.195 & -5 \\
\hline Sharpe M & 0.224 & -1 & 0.08 & -2 & -0.004 & -3 & Sharpe M & 0.005 & -4 & 0.454 & -6 & 0.014 & -1 & 0.207 & -2 & 0.013 & -3 & 0.205 & -5 \\
\hline Sortino & 1.221 & -1 & 1.514 & -2 & -0.837 & -3 & Sortino & 0.134 & -4 & 0.996 & -5 & 1.107 & -1 & 1.171 & -2 & 0.153 & -3 & 0.524 & -6 \\
\hline Sharpe S/K & 0.195 & -2 & 0.051 & -1 & -0.13 & -3 & Sharpe S/K & 0.031 & -3 & 0.386 & -5 & 0.038 & -1 & 0.139 & -2 & 0.055 & -6 & 0.095 & -4 \\
\hline Calmar & 0.519 & -2 & 0.899 & -1 & -0.342 & -3 & Calmar & 0.114 & -5 & 0.649 & -3 & 1.104 & -1 & 0.933 & -2 & 0.001 & -4 & 0.082 & -6 \\
\hline Sterling & 0.509 & -1 & 0.477 & -2 & -0.279 & -3 & Sterling & 0.001 & -5 & 0.886 & -3 & 0.009 & -1 & 0.066 & -2 & 0.101 & -4 & 0.032 & -6 \\
\hline RI & 0.009 & -1 & -0.087 & -2 & -0.014 & -3 & RI & 0.116 & -4 & 0.22 & -6 & 0.094 & -1 & 0.203 & -2 & 0.124 & -3 & 0.209 & -5 \\
\hline Treynor & 0.148 & -2 & -0.019 & -1 & -0.103 & -3 & Treynor & 0.017 & -5 & 0.52 & -4 & 0.016 & -3 & 0.104 & -2 & 0.042 & -1 & 0.124 & -5 \\
\hline Jensen & 0.058 & -1 & -0.021 & -2 & -0.03 & -3 & Jensen & 0.103 & -5 & 0.279 & -3 & 0.101 & -2 & 0.186 & -1 & 0.193 & -4 & 0.176 & -5 \\
\hline Sharpe VaR & 0.137 & -1 & -0.034 & -2 & -0.088 & -3 & Sharpe VaR & 0.007 & -4 & 0.359 & -6 & 0.011 & -1 & 0.171 & -2 & 0.039 & -3 & 0.135 & -5 \\
\hline R Var & 0.126 & -1 & 0.066 & -2 & -0.085 & -3 & R Var & 0.104 & -4 & 0.342 & -5 & 0.102 & -1 & 0.163 & -2 & 0.075 & -3 & 0.132 & -6 \\
\hline Sharpe Var C/F & 0.528 & -1 & 0.385 & -2 & -2.267 & -3 & Sharpe Var C/F & 0.007 & -4 & 0.779 & -6 & 0.006 & -1 & 0.285 & -2 & 0.285 & -3 & 1.226 & -5 \\
\hline STARR ratio & 0.082 & -1 & 0.007 & -2 & -0.057 & -3 & STARR ratio & 0.103 & -4 & 0.292 & -5 & 0.101 & -1 & 0.176 & -2 & 0.084 & -3 & 0.154 & -5 \\
\hline Omega & 1.039 & -3 & 0.859 & -2 & 0.974 & -1 & Omega & 1.033 & -4 & 1.265 & -6 & 0.969 & -1 & 1.752 & -2 & 1.037 & -3 & 1.225 & -5 \\
\hline « d » ratio & 0.856 & -1 & 0.752 & -2 & 0.997 & -3 & «d » ratio & 0.917 & -4 & 1.002 & -6 & 1.008 & -1 & 1.122 & -2 & 1.005 & -4 & 1.12 & -3 \\
\hline M2 & 0.068 & -1 & -0.133 & -2 & 0.002 & -3 & M2 & 0.016 & -5 & 0.281 & -6 & 0.016 & -1 & 0.225 & -2 & 0.007 & -3 & 0.215 & -5 \\
\hline MRAP & 0.172 & -2 & 0.117 & -1 & -0.079 & -3 & MRAP & 0.132 & -4 & 0.537 & -4 & 0.122 & -3 & 0.121 & -2 & 0.097 & -1 & 0.14 & -6 \\
\hline eSDAR & 0.047 & -1 & -0.154 & -2 & -0.019 & -3 & eSDAR & 0.005 & -5 & -0.259 & -6 & -0.006 & -1 & 0.204 & -2 & 0.014 & -3 & -0.194 & -5 \\
\hline AP & -0.005 & -1 & -0.115 & -2 & -0.08 & -3 & $\mathrm{AP}$ & 0.061 & -4 & -0.202 & -6 & 0.044 & -1 & 0.129 & -2 & 0.04 & -3 & -0.124 & -4 \\
\hline ASKSR & 0.506 & -1 & 0.424 & -2 & 0.365 & -3 & ASKSR & 0.078 & -5 & 0.742 & -6 & 0.08 & -2 & 0.336 & -1 & 0.089 & -3 & 0.503 & -4 \\
\hline Observations & \multicolumn{2}{|c|}{2634} & \multicolumn{2}{|c|}{2634} & \multicolumn{2}{|c|}{2634} & Observations & \multicolumn{2}{|c|}{2634} & \multicolumn{2}{|c|}{2634} & \multicolumn{2}{|c|}{2634} & \multicolumn{2}{|c|}{2634} & \multicolumn{2}{|c|}{2634} & \multicolumn{2}{|c|}{2634} \\
\hline
\end{tabular}

The values given in parentheses refer to the classification of an Islamic index for each of the performance measures.

Table 6: Performance measures applied to Islamic market indices by market capitalization (6-1) and region (6-2) of the Dow John family.

Regional Islamic indices: Overall, the regional stock indices belonging to the Dow Jones family show satisfactory returns over the entire period (Tables 2-6). This is testified by the positive values of traditional performance measures.

The indices of companies in the Latin American region (DJIGLA) and Australian companies (DJIGAU) are the best performers, their ratios of Calmar and Sortino are greater than 1. The DJIGLA index is the most risky but this excess of risk is rewarded by higher returns among regional indices.
Performance of DJIGLA index is greater when the measure of risk used is the standard deviation, semi-variance, $\mathrm{VaR}, \mathrm{CVaR}$ or the max drawdown. However, this index is characterized by a beta higher than other indices, it follows a slightly lower Treynor ratio and alpha Jensen.

The worst performances were displayed by indices of companies in the Nordic countries (DJIGNO) and the American continent (DJIGAM) that are penalized by, respectively, a higher risk and a lack of profitability. 
Thus, these two indices have an AP and eSDAR ratios negative meaning underperformance compared with the benchmarks used. The classification obtained by the Sharpe ratio is observed by 10 other measures.

The DJIGLA index arrives top ranking and is considered the most powerful in 17 measures, while DJIGNO index is considered the worst performer among the regional indices by 13 performance measures.

\section{Performance persistence of Islamic stock index}

Using the methodology of Carmichael et al. [16], we studied the persistence of performance of the DJI100 index. Thus, we created four portfolios according to risk factors of the Carhart model [14], namely the market (RM-RF), firm size (SMB), the management style or value effect (HML) and the inertia effect commonly known as Momentum (UMD). We first present descriptive statistics portfolios composed before moving to the regression model. Table 7 summarizes the descriptive statistics and correlations between the four factors:

$\mathrm{RF}$ is the risk-free rate of return, $\mathrm{RM}$ represents the profitability of the market, SMB is the size, HML is the factor value calculated annually, UMD is the Momentum factor calculated monthly for all 100 values of the Islamic index DJI100, t-stat is calculated by dividing the mean by its own standard error ESM (ESM is calculated by dividing the standard deviation by the square root of the sample size, $\mathrm{N}=139$ ). Data are based on monthly returns from January 2004 to December 2014 (Tables 7 and 8).

Table 7 shows that the market risk premium is lower than other risk factors. Other premiums are positive and the premium Momentum factor is the highest. The risk factor associated with company size (SMB) shows that small caps outperform large cap stocks, the difference is $0.52 \%$ per month $(6.24 \%$ per year and with a t-stat of 0.55). This difference is significantly greater but less than 4.92\% (t-stat: 1.72) that found by Fama and French [20] (t-stat: 1.28). Similarly, the analysis of the HML factor positive sign also shows that companies with a value management style perform better on average than the growth enterprises. The difference is $0.11 \%$ per month $(1.32 \%$ per annum with a t-stat of 0.14 ). It is less important and less significant than the values reported by Fama and French [20] who found in their study a difference of $6.33 \%$ with a t-stat value of 2.60 .

The Momentum factor is also positive. It shows that, on average, the companies having had the higher returns over the past 12 months, continued performance during the same period. The difference constituting the premium Momentum came to $5.52 \%$.

When we look at the standard deviation means, we find that with a standard deviation of $2.71 \%$ per month (32.52\% annually), the SMB factor is less volatile than the market risk premium $(5.82 \%$ in the corresponding month to $69.84 \%$ per year) and that the SMB factor calculated by Fama and French [20], which amounts to $15.44 \%$. However, the HML factor with a standard deviation of $5.16 \%$ per month (91.92\% annually), is less risky than the same factor calculated by Fama and French [20], with standard deviation rising to $13.11 \%$. Also, we observed very low correlations between the four factors as shown in Table 8. This result is not surprising considering the way we have built these four factors. Indeed, we have neutralized the effect size when calculating the value and Momentum factors. This low correlation between the four factors was raised by Carhart [14] and confirmed by Carmichael et al. [16] on the Canadian market.

Furthermore, researchers have highlighted the existence of seasonality in the Momentum factor. Thus, Jegadeesh and Titman [21]

\begin{tabular}{|l|c|c|c|}
\hline & RM-RF & SMB & HML \\
\hline Average & -0.02155 & 0.005211 & 0.001121 \\
\hline Standard deviation & 0.058211 & 0.027134 & $0.055215^{*}$ \\
\hline t-stat & -1.30004 & 0.552147 & 0.051664 \\
\hline *Indicates a significance level of 10\%. & & 0.142114 \\
\hline
\end{tabular}

*Indicates a significance level of $10 \%$.

Table 7: Descriptive statistics among the four factors RM-RF, SMB, HML and UMD

\begin{tabular}{|c|c|c|c|}
\hline & RM-RF & SMB & HML \\
\hline RM-RF & 1 & 0.088215 & 0.142215 \\
\hline SMB & & 1 & -0.06614 \\
\hline HML & & & 0.055842 \\
\hline UMD & & & -0.21412 \\
\hline
\end{tabular}

Table 8: Correlations among the four factors RM-RF, SMB, HML and UMD.

\begin{tabular}{|c|c|c|c|c|c|c|c|c|c|c|c|c|}
\hline & \multicolumn{4}{|c|}{ Average } & \multicolumn{4}{|c|}{ Standard deviation } & \multicolumn{4}{|c|}{ ESM } \\
\hline & RM-RF & SMB & HML & UMD & RM-RF & SMB & HML & UMD & RM-RF & SMB & HML & UMD \\
\hline January & $-0.0414^{*}$ & $0.0221^{*}$ & $-0.0122^{*}$ & $0.0211^{*}$ & $0.1245^{\star}$ & $0.1914^{*}$ & $0.0212^{*}$ & $0.3472^{*}$ & $0.1245^{*}$ & $0.1178^{*}$ & $0.1214^{*}$ & $0.1318^{*}$ \\
\hline February & $-0.0325^{*}$ & $-0.0011^{*}$ & $0.0115^{*}$ & $0.0321^{*}$ & $0.1925^{*}$ & $0.2962^{*}$ & $0.3841^{*}$ & $0.4213^{*}$ & $0.1273^{*}$ & $0.1267^{*}$ & $0.1342^{*}$ & $0.1346^{*}$ \\
\hline March & $-0.0034^{*}$ & $0.0033^{*}$ & $0.0140^{*}$ & $0.0214^{*}$ & $0.2231^{*}$ & $0.1913^{*}$ & $0.2482^{*}$ & $0.2017^{*}$ & $0.1301^{*}$ & $0.1187^{*}$ & $0.1235^{\star}$ & $0.2015^{\star}$ \\
\hline April & $-0.0011^{*}$ & $-0.0033^{*}$ & $0.0011^{*}$ & $0.0274^{*}$ & $0.1625^{*}$ & $0.2238^{*}$ & $0.3692^{*}$ & $0.2611^{*}$ & $0.1273^{*}$ & $0.1206^{*}$ & $0.1328^{*}$ & $0.1236^{*}$ \\
\hline May & $-000103^{*}$ & $0.0111^{*}$ & $0.0177^{*}$ & $0.0088^{*}$ & $0.1250^{*}$ & $0.3275^{\star}$ & $0.3420^{*}$ & $0.4027^{*}$ & $0.1339^{*}$ & $0.1294^{*}$ & $0.1235^{*}$ & $0.1359^{*}$ \\
\hline June & $-0.0411^{*}$ & $0.0151^{*}$ & $-0.0312^{*}$ & $0.0521^{*}$ & $0.1677^{*}$ & $0.2447^{*}$ & $0.3017^{*}$ & $0.4034^{*}$ & $0.1275^{*}$ & $0.1224^{*}$ & $0.1272^{*}$ & $0.1342^{*}$ \\
\hline July & $-0.0182^{*}$ & $0.0312^{*}$ & $0.0001^{*}$ & $0.0412^{*}$ & $0.1422^{*}$ & $0.3267^{*}$ & $0.2525^{*}$ & $0.3843^{*}$ & $0.1315^{*}$ & $0.1294^{*}$ & $0.1258^{*}$ & $0.1218^{*}$ \\
\hline August & $-0.0369^{*}$ & $0.0162^{*}$ & $0.0125^{*}$ & $0.0120^{*}$ & $0.2145^{*}$ & $0.2528^{*}$ & $0.2366^{*}$ & $0.2384^{*}$ & $0.1845^{*}$ & $0.1239^{*}$ & $0.1216^{*}$ & $0.1218^{*}$ \\
\hline September & $-0.0311^{*}$ & $0.0012^{*}$ & $-0.0055^{\star}$ & $0.0224^{*}$ & $0.8336^{*}$ & $0.1977^{*}$ & $0.2906^{*}$ & $0.2382^{*}$ & $0.1352^{*}$ & $0.1183^{*}$ & $0.1262^{*}$ & $0.1241^{*}$ \\
\hline October & $-0.0124^{*}$ & $-0.0231^{*}$ & $0.0014^{*}$ & $0.0589^{*}$ & $0.2568^{*}$ & $0.2334^{*}$ & $0.2738^{*}$ & $0.2993^{*}$ & $0.1326^{*}$ & $0.1214^{*}$ & $0.1248^{*}$ & $0.1276^{*}$ \\
\hline November & $-0.0188^{*}$ & $0.0122^{*}$ & $-0.0022^{*}$ & $0.0956^{*}$ & $0.2178^{*}$ & $0.2502^{*}$ & $0.2437^{*}$ & $0.2653^{*}$ & $0.1303^{*}$ & $0.2297^{*}$ & $0.1222^{*}$ & $0.1198^{*}$ \\
\hline December & $0.0109^{*}$ & $-0.0061^{*}$ & $0.0212^{*}$ & $0.0614^{*}$ & $0.2911^{*}$ & $0.2237^{*}$ & $0.2699^{*}$ & $0.2993^{*}$ & $0.1283^{*}$ & $0.1205^{*}$ & $0.1245^{*}$ & $0.1233^{*}$ \\
\hline
\end{tabular}

${ }^{*}$ Mark indicates significance levels to $10 \%$. P-values are in parentheses. 
found that portfolios winners outperformed losers every month except January, the month in which the trend is reversed. The researchers called this the "January effect" or the pass effect in the new year "turnof-the-year" and confirmed in subsequent research [22].

With the objective of highlighting this seasonality, we studied the four factors by month (Table 9).

Table 9 shows results consistent with those of Jegadeesh and Titman [21] by which the winner portfolios outperform the losers, demonstrated by the values of the Momentum which are all positive. This result is true for all 12 months of which 8 are significant at $1 \%$. However, we observe no reverse trend in January following the transition to the new year unlike the seasonality emphasized in financial literature $[21,22]$.

The regression results show that the alpha model is negative and significant, this means that filtering by the standards of Islamic Finance, which is to exclude some sectors, led to negative returns (Table 10). As with most ethical investments, this is due, mainly, to a lack of diversification [23]. Several researchers agree on the fact that the differences between ethical and conventional investments are not significant. In the financial literature, very few alphas are significant, and when they are significant, their sign is negative [24].

We perform the following regression according to the $\mathrm{ARCH}$ model (2):

$$
\left(\mathrm{R}_{\mathrm{t}}-\mathrm{R}_{\mathrm{ft}}\right)=\alpha+\beta\left(\mathrm{R}_{\mathrm{tt}}-\mathrm{R}_{\mathrm{ft}}\right)+\beta_{\mathrm{s}} \mathrm{SMB}_{\mathrm{t}}+\beta_{\mathrm{h}} \mathrm{HML}_{\mathrm{t}}+\beta_{\mathrm{u}} \mathrm{UMD}_{\mathrm{t}}+\varepsilon_{\mathrm{t}}
$$

Also, the market premium is significantly positive, which can be interpreted in the light of financial theory which considers that the high returns associated with investments where the risk is high.

We introduce subsequently a dummy variable to represent the recession. Indeed, we add to the previous model a dummy variable (D ') which will be equal to 1 if there is a recession and zero otherwise. The periods of rising and falling correspond to the periods set by the National Bureau of Economic Research (NBER).

Table 11 shows the results of the new regression taking into account the economic cycle. Indeed, when we introduce the dummy variable (D'), we see that $\beta$ remains significant corroborating the results found previously (Table 11) except that $\alpha$ is not more significant. Additional information is given by $\alpha^{\prime}$ and $\beta^{\prime}$ that are negative and significant. $\beta^{\prime}$ is significant and negative. Its comparison with $\beta$ shows that the risk premium is more important in periods of expansion and, during the recession periods, the profitability of the index component companies is less than the assumed risk-free rate.

We perform the following regression according to the $\mathrm{ARCH}$ model (2):

$\left(\mathrm{R}_{\mathrm{t}}-\mathrm{R}_{\mathrm{ft}}\right)=\alpha+\beta\left(\mathrm{R}_{\mathrm{mt}}-\mathrm{R}_{\mathrm{ft}}\right)+\beta\left(\mathrm{R}_{\mathrm{mt}}-\mathrm{R}_{\mathrm{ft}}\right)+\beta_{\mathrm{s}} \mathrm{SMB}_{\mathrm{t}}+\beta_{\mathrm{h}} \mathrm{HML}_{\mathrm{t}}+\beta_{\mathrm{u}} \mathrm{UMD}_{\mathrm{t}}+$

$\alpha^{\prime} \mathrm{D}_{t}^{\prime}+\beta^{\prime} D_{t}^{\prime}\left(R_{m t}-R_{f t}\right)+\beta_{s}^{\prime} D_{t}^{\prime} S M B_{t}+\beta_{h}^{\prime} D_{t}^{\prime} H M L_{t}+\beta_{t}^{\prime} D_{t}^{\prime} U M D_{t}+\varepsilon_{t}$
We also note that the underperformance is more pronounced in times of crisis ( $\alpha$ ' negative and significant), which is mainly explained by two reasons. The first is that the filters used by Islamic Finance for the selection of companies result in a lack of diversification, leading to underperformance in accordance with financial theory [23]. The second reason is that the exclusion concerns those companies belonging to illegal sectors that are considered to be the most resilient in recessionproof [24-39].

\section{Conclusion}

Throughout this work, we have seen that the first ethical commitments were of religious origin. This what has led us to work on Islamic Finance, regarded as a morally responsible Finance and forming integral part of the ethical Finance. We have focused our attention on Islamic indices. We were interested by their specificity compared to their conventional counterparts, their profitability, their risk, their performance and the persistence of this latter.

In order to compare Islamic market indices among themselves, we used a battery of 21 performance measures. On the whole, the indices of emerging countries in the Dow Jones family display the best performers, while those of US companies have the lowest performance (Table 5). The breakdown by geographical area shows a good performance for the indices of basic materials and poor performance for the financial ones (Table 6). Regarding the geographical distribution (Table 7), the best performing indices are those of Latin America and the worstperforming are those including the companies of Nordic countries. As for the distribution by size, the Dow Jones indexing of small caps perform better than large caps.

Then, we looked at the question of the performance persistence. We used the four-factor model of Carhart [14] that brings out a negative and significant alpha synonym for negative returns (Table 9). Taking account of the economic situation by introducing a dummy variable, shows that alpha is negative and significant only in times of recession. This means that the underperformance of the Islamic index is more pronounced during periods of market decline. The risk premium is, in turn, greater during booms. However, no evidence is given as regards the other three factors (size, Book to Market and Momentum) that remain insignificant.

Our work contributes to the literature by providing answers to several issues that were pending and not yet processed by the researchers. Thus, this is the first time that a Meta-analysis was realized to provide a quantitative summary of the literature in this field. It is also the first study based on such a large sample of Islamic equity indices covering major families of known indices. Indeed, besides the Dow Jones and FTSE, widely studied in the literature, we reviewed Islamic indices of Standard and Poor's and MSCI family not yet treated in the academic literature. As for Islamic investment funds, our work is also a first investigation of the continued performance of this category of funds.

\begin{tabular}{|c|c|c|c|}
\hline$-0.0124^{* * *}$ & $0.4509^{* * *}$ & 0.11207 & -0.0041 \\
\hline-0.0022 & 0 & -0.2211 & -0.1008 \\
\hline${ }^{* * *}$ Respectively indicate significance levels to $1 \%$. P-values are in parentheses. \\
\hline
\end{tabular}

Table 10: Regression results of the four-factor model of Carhart.

\begin{tabular}{|l|c|c|c|c|c|c|c|c|c|}
-0.009 & $0.411^{* * *}$ & 0.073 & 0.002 & -0.088 & $-0.019^{*}$ & $-0.261^{*}$ & 0.411 & -0.054 & -0.204 \\
\hline-0.112 & 0 & -0.411 & -0.982 & -0.211 & -0.071 & -0.108 & -0.914 & -0.743 & -0.499 \\
\hline
\end{tabular}

${ }^{*},{ }^{* * *}$ Respectively indicate significance levels to $10 \%$, and $1 \%$. P-values are in parentheses.

Table 11: Regression results of the four-factor model of Carhart with introduction of dummy variable representing the recession 
However, this article, like all research, has certain limitations mainly related to lack of data. Regarding Islamic indices, we had no data on the composition of all indices in our sample. Another limitation, which follows from the first, is the lack of data on dividends paid by companies within Islamic indices. The limitations of this work constitute research directions to be discussed and on which we have already started thinking.

\section{References}

1. Abdelhafid $N$ (2010) Les marchés financiers et les fonds d'investissement islamiques. La revue du financier 185: 89-98.

2. Albaity M, Ahmad R (2008) Performance of Syariah and composite indices: Evidence from Bursa Malaysia. Asian Academy of Management Journal of Accounting and Finance 4: 23-43.

3. Atta H (2000) Ethical Rewards: an Examination of the Effect of Islamic Ethical Screens on Financial Performance and of Conditioning Information on Performance measures. University of Durham, Department of Economics and Finance.

4. Hussein K, Omran M (2005) Ethical investment revisited: evidence from Dow Jones Islamic indexes. The Journal of Investing 14: 105-126.

5. Abedifar P, Ebrahim S, Molyneux P, Tarazi A (2015) Islamic banking and Finance: recent empirical literature and directions for future research. Journal of Economic Surveys 29: 637-670.

6. Hong H, Kacperczyk M (2009) The price of sin: The effects of social norms on markets. Journal of Financial Economics 93: 15-36.

7. Ho CSF, Rahman NAA, Yusuf NHM, Zamzamin Z (2014) Performance of global Islamic versus conventional share indices: International evidence. Pacific-Basin Finance Journal 28: 110-121.

8. Girard EC, Hassan MK (2008) Is there a cost to faith-based investing: Evidence from FTSE Islamic indices. The Journal of Investing 17: 112-121.

9. Binmahfouz S, Hassan MK (2012) A comparative study between the investment characteristics of Islamic and socially responsible investment portfolios: Evidence from FTSE indices family. In International Conference on Islamic Capital Markets, pp: 19-20.

10. Ljung GM, Box GE (1978) On a measure of lack of fit in time series models. Biometrika 65: 297-303.

11. Dickey DA, Fuller WA (1981) Likelihood ratio statistics for autoregressive time series with a unit root. Econometrica: Journal of the Econometric Society, pp: 1057-1072.

12. Jarque CM, Bera AK (1980) Efficient tests for normality, homoscedasticity and serial independence of regression residuals. Economics letters 6: 255-259.

13. Scholz H, Wilkens M (2005) A jigsaw puzzle of basic risk-adjusted performance measures. The Journal od Performance Measurement.

14. Carhart MM (1997) On persistence in mutual fund performance. The Journa of Finance 52: 57-82

15. Fama EF, French KR (1993) Common risk factors in the returns on stocks and bonds. Journal of Financial Economics 33: 3-56.

16. Carmichael B, Coën A, L'Her JF (2008) Erreurs sur les variables et modèles d'évaluation des actifs financiers canadiens. Papier de recherche, Québec.

17. Aftalion F, Poncet $P$ (1991) Les mesures de performance des OPCVM (problèmes et solutions). Revue Banque 517: 582-588.

18. Treynor JL (1965) How to rate management of investment funds. Harvard business review 43: 63-75.
19. Young T (1991) Calmar ratio: A smoother tool. Future Magazine.

20. Fama EF, French KR (1996) Multifactor explanations of asset pricing anomalies. The Journal of Finance 51: 55-84.

21. Jegadeesh N, Titman S (1993) Returns to buying winners and selling losers: Implications for stock market efficiency. The Journal of Finance 48: 65-91.

22. Jegadeesh N, Titman S (2001) Profitability of momentum strategies: An evaluation of alternative explanations. The Journal of Finance 56: 699-720.

23. Barnett ML, Salomon RM (2006) Beyond dichotomy: The curvilinear relationship between social responsibility and financial performance. Strategic Management Journal 27: 1101-1122.

24. Le Sourd V (2011) Performance of socially responsible investment funds against an efficient SRI index: The impact of benchmark choice when evaluating active managers. EDHEC-Risk and Asset Management Research Centre, Nice.

25. Salaber J (2008) Ethics and portfolio management: investor behavior and profitability of the investment politically incorrect (Doctoral dissertation, ParisDauphine).

26. Abderrezak F (2008) The performance of Islamic equity funds: A comparison to conventional, Islamic and ethical benchmarks.

27. Abdullah F, Hassan T, Mohamad S (2007) Investigation of performance of Malaysian Islamic unit trust funds: Comparison with conventional unit trust funds. Managerial Finance 33: 142-153.

28. Collina S (2009) Islamic equity funds: an Italian perspective. Munich Personal RePEc Archive.

29. Elfakhani S, Hassan MK, Sidani Y (2005) Comparative performance of Islamic versus secular mutual funds. In 12th Economic Research Forum Conference in Cairo, Egypt, pp: 19-21.

30. Eurekahedge (2010) Overview of 2009 Key Trends in Islamic Funds.

31. Hayat R (2006) An empirical assessment of Islamic equity fund returns. Failaka website, pp: 1-69.

32. Hayat R, KraeussI R (2011) Risk and return characteristics of Islamic equity funds. Emerging Markets Review 12: 189-203.

33. Hoepner AGF, Rammal HG, Rezec M (2011) Islamic mutual funds' financial performance and international investment style: Evidence from 20 countries. The European Journal of Finance 17: 829-850.

34. Hussein KA (2007) Islamic investment: evidence from Dow Jones and FTSE indices. Islamic Economics and Finance.

35. Iftikar N, Amin UAIA, Shah SS (2012) Comparative Performance Evaluation of Islamic VS Conventional Mutual Funds (2003 - 2010): A Case of Pakistan, International Conference on Islamic Capital Markets

36. Mansor F, Bhatti MI (2011) Islamic Mutual Funds Performance for Emerging Market, During Bullish and Bearish: The Case of Malaysia. In 2nd International Conference on Business and Economic Research, pp: 14-16.

37. Merdad H, Hasan MK, Alhenawi Y (2010) Islamic versus conventional mutual funds performance in Saudi Arabia: a case study. Islamic Economics.

38. Muhammad NMN, Mokhtar M (2008) Islamic equity mutual fund performance in Malaysia: Risk and return analysis. In The Midwest Finance Association (MFA) Conference.

39. Saad NM, Majid SAbdM, Kassim S, Hamid Z, Yusof RM (2010) A comparative analysis of the performance of conventional and Islamic unit trust companies in Malaysia. International Journal of Managerial Finance 6: 24-47. 